\title{
Minimally Invasive Precise Application of Bioadhesives to Prevent IPPROM on a Pregnant Sheep Model
}

\author{
Yannick R. Devaud ${ }^{a, b}$ Senta Stäuble ${ }^{a, b} \quad$ Ueli Moehrlen ${ }^{b, c, d}$ \\ Miriam Weisskopf ${ }^{b}$, e Ladina Vonzun ${ }^{\text {a, b, d }}$ Roland Zimmermanna, b, d \\ Martin Ehrbara,b, d Nicole Ochsenbein-Kölble ${ }^{a, b, d}$
}

${ }^{a}$ Department of Obstetrics, University Hospital Zurich, Zurich, Switzerland; 'b University of Zurich, Zurich, Switzerland; 'Pediatric Surgery, University Children's Hospital Zurich, Zurich, Switzerland; ' $T$ The Zurich Center for Fetal Diagnosis and Therapy, Zurich, Switzerland; ${ }^{e}$ Center of Surgical Research, University Hospital Zurich, Zurich, Switzerland

\section{Keywords}

latrogenic preterm prelabor rupture of the membranes .

Minimally invasive therapy · Fetoscopy · Bioadhesive ·

Sheep model

\begin{abstract}
Introduction: latrogenic preterm premature rupture of the membrane remains the Achille's heel of fetoscopy. The aim of this study was to show in vivo feasibility of fetal membrane (FM) defect sealing by the application of tissue glues with umbrella-shaped receptors. Methods: First, we adapted our previously described ex vivo strategy and evaluated the adhesion strength of different tissue glues, Histoacryl ${ }^{\circledR}$ and Glubran $2^{\circledR}$, by bonding polytetrafluoroethylene or silicone encapsulated nitinol glue receptor to human FM. Then, we exposed pregnant sheep uterus through a laparotomy and placed a 10-French trocar into the amniotic cavity through which the umbrella-shaped glue receptor $(n=9)$ was inserted and fixated onto the FM with the tissue glues $(n=8)$. The tightness of the sealed defects was assessed $4 \mathrm{~h}$ post-surgery. Results: Both tissue glues tested resulted in adhesion of the glue receptors to the FM ex vivo. In vivo, all glue receptors opened in the amniotic cavity $(n=9)$ and all success-
\end{abstract}

fully placed glue receptors sealed the FM defect $(n=8)$. Four hours post-surgery, 2 treatment sites showed minimal leakage whereas the negative control without glue $(n=1)$ showed substantial leakage. Discussion: This in vivo study confirms that fetoscopically induced FM defects can be sealed by the application of tissue adhesives.

(C) 2021 The Author(s).

Published by S. Karger AG, Basel

\section{Introduction}

If fetal or placental anomalies are discovered during pregnancy, fetal surgery can offer life-improving or lifesaving options. Currently, these prenatal interventions are performed either by opening the uterus or fetoscopically depending on the indication. For example, fetoscopic laser surgeries have become the standard approach for the treatment of twin-twin transfusion syndrome [1]. Despite big promises in the treatment outcomes, those surgeries come with their own set of problems [2]. During the procedures, each access site causes a defect in the fetal membrane (FM) that does not spontaneously heal [3]. These defects lead to iatrogenic preterm prelabor rupture of the membranes (iPPROM) in $30-100 \%$ of all fetosco-
(C) 2021 The Author(s)

Published by S. Karger AG, Basel

This is an Open Access article licensed under the Creative Commons Attribution-NonCommercial-4.0 International License (CC BY-NC) (http://www.karger.com/Services/OpenAccessLicense), applicable to the online version of the article only. Usage and distribution for commercial purposes requires written permission.
Correspondence to:

Martin Ehrbar, martin.ehrbar@usz.ch 


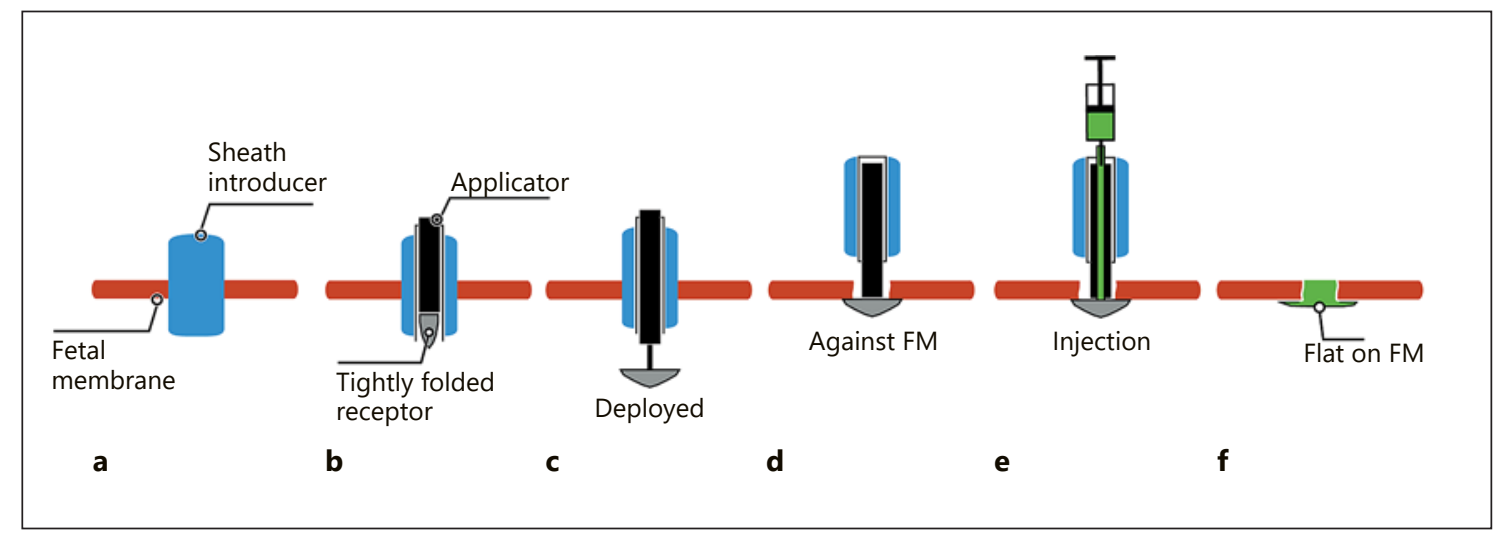

Fig. 1. The previously described device was adapted for easier handling during surgery. All the functionalities were integrated into one device called the applicator. a, b The applicator is inserted through the 10-Fr sheath introducer which was previously placed in the amniotic cavity through the uterine wall. c, d The receptor is then deployed into the cavity and placed against the membrane. e, $\mathbf{f}$ At this point, the surgeon applies the adhesive from the outside and pulls the receptor flat against the FM. FM, fetal membrane.

pies depending on the type of surgery, number and diameter of used ports, and the definition of "premature rupture" [4]. Many different approaches, such as adhesives, patches, or different plugs to close the defects have been tried [5-15] to limit iPPROM rate, but currently none of these methods are regularly used clinically due to instability, side reactions, or inefficacy [16]. Several studies have focused on sealants as an option to close the defect [12, $14,15]$. One major challenge that remains to be addressed is the delivery method of those sealants to the site of the defect. We previously demonstrated a method to deliver a sealing adhesive through the fetoscopy port using an umbrella-shaped glue receptor as a patch in an ex vivo setting [17]. This method enables the precise delivery in a minimally invasive way to apply the adhesive, seal the defect, and potentially stabilize the FM.

Here, we refined the device and investigated the most suitable combinations of bioadhesives and materials that provide sufficient adhesion strength ex vivo. We then conducted an in vivo application of the device on a pregnant sheep model to prove the potential of the method.

\section{Materials and Methods}

Devices for the Minimally Invasive Sealing of Membrane

Defect

Applicator and Injector

We previously described a device for the preventive sealing of FM defects after fetoscopic interventions. This device comprised a glue receptor, an applicator to introduce the glue receptor, and an injection system to deliver the adhesive inside the amniotic cavity [17]. The glue receptor was designed in a $20 \mathrm{~mm}$-diameter um- brella shape for optimized folding with the concave part of the umbrella facing the FM. The edges of the umbrella are rounded to prevent injury of the FM and to ensure optimal distribution of the glue on the glue receptor surface. The umbrella was produced out of nitinol, which gives it superelastic properties, enabling it to be folded into a 10-Fr catheter, and to be deployed automatically when pushed into the amniotic cavity. This device was improved for optimal use by the surgeon (Fig. 1). The umbrella-shaped glue receptor was loaded into a stainless-steel tube with an outer diameter of $3.20 \mathrm{~mm}$ and an inner diameter of $3.00 \mathrm{~mm}$. This tube slid freely in the 10-Fr sheath introducer used for fetoscopic interventions (in blue, Check-Flo Performer ${ }^{\circledR}$ Introducer; Cook Medical, Bloomington, IN, USA). Another stainless-steel tube of outer diameter of $2.90 \mathrm{~mm}$ and inner diameter of $2.70 \mathrm{~mm}$ was used to push and eject the umbrella-shaped glue receptor. The umbrellashaped glue receptor was connected to the pushing tube by a degradable suture wire to keep the umbrella-shaped glue receptor connected to the applicator. A syringe was connected to a tube of $1.00 \mathrm{~mm}$ outer diameter and $0.50 \mathrm{~mm}$ inner diameter, which was inserted in the second metal tube. This was used to inject the adhesive (green on Fig. 1) once the umbrella-shaped glue receptor was in place against the membrane. Once this was done, the user was able to release its connection to the applicator via a lock system. The above mentioned elements were integrated in a custommade handle, operable with one hand. All the parts were assembled in a clean room and sterilized by autoclave.

Umbrella-Shaped Glue Receptor for the Gathering of Sealing Materials

The umbrella-shaped glue receptors were made up of a frame and a coating. The frames were laser cut from a nitinol sheet of 200 $\mu \mathrm{m}$ thickness and shape set. This superelastic material enables its crimping into a tube that fits into a $10-\mathrm{Fr}$ sheath introducer and its automatic deployment once pushed inside the amniotic sac. Polytetrafluoroethylene (PTFE) and silicone were tested as coating options. The PTFE coating was made of 2 electrospun sheets laminated together around the nitinol frame using a thermoplastic 


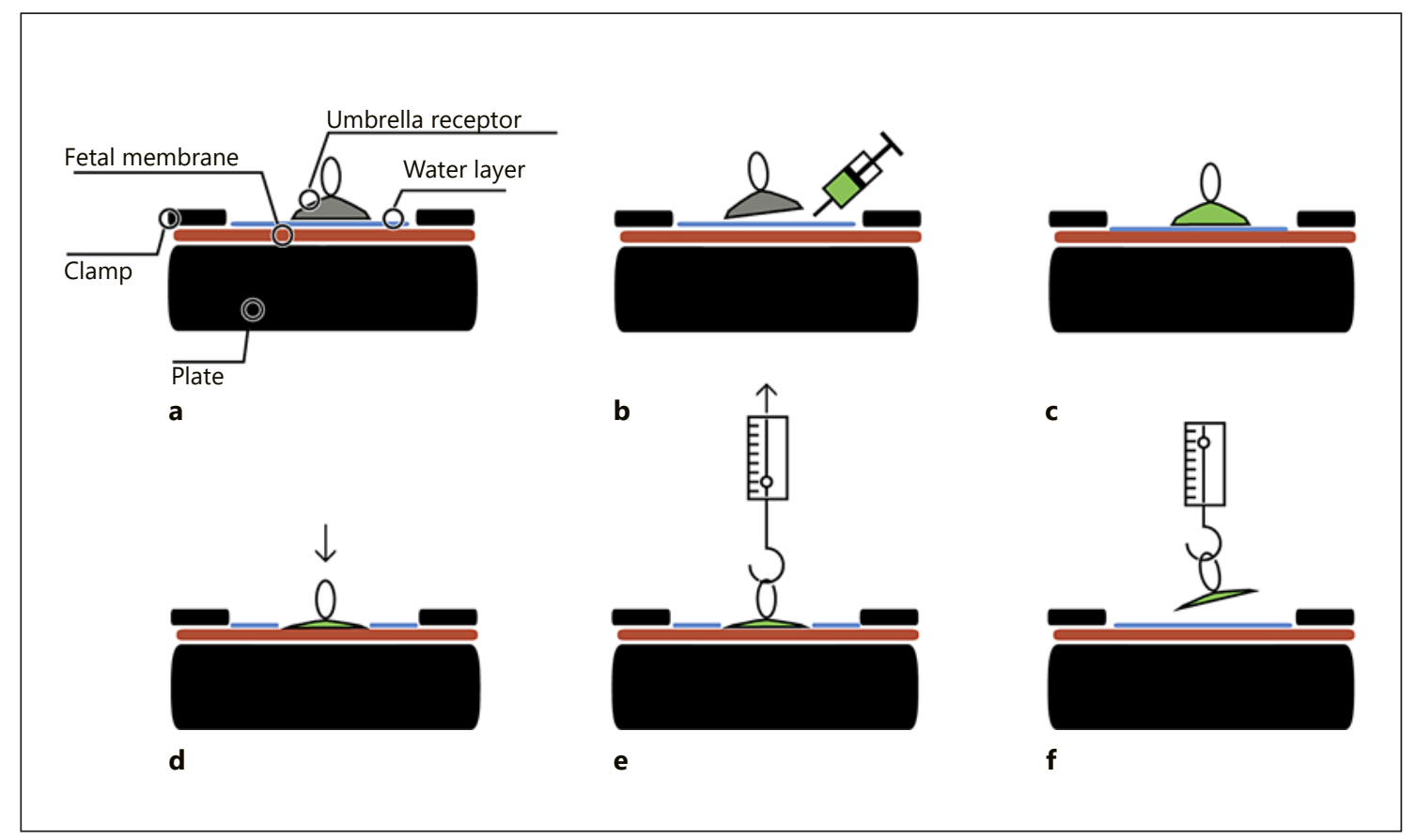

Fig. 2. Adhesion strength test experimental setup. a The FM is clamped with the amnion up in an aluminum cylinder. $\mathbf{b}$ The adhesive is injected in the concave part of the receptor, filling it, as seen in c. d The umbrella receptor is laid flat to minimize the glue layer and maximize adhesion strength. This step is enabled by the plastic plate placed underneath the FM. e Adhesion strength is then measured with a dynamometer to measure the force at rupture, seen in f. FM, fetal membrane.

(Zeus Indutrial Products Inc., Orangeburg, SC, USA). The silicone sheets were placed on the frames using a dip-coating method (Medibrane, Rosh Haayin, Israel).

\section{Bioadhesives}

Based on previous studies of potential adhesives for the use in fetoscopy, we chose Histoacryl ${ }^{\circledR}$ (B. Braun Surgical S.A., Rubi, Spain) and Glubran $2^{\circledR}$ (GEM SRL, Viareggio, Italy) $[17,18]$. Both are cyanoacrylate-based adhesives that are CE marked and used internally for other indications such as net fixation for inguinal hernia repair procedures [19]. They were selected due to their strong adhesive ability and their fast curation time upon contact with wet environments (1-2 s) [20,21]. In all our experiments, the adhesives were transferred from ampoules to syringes for their application.

\section{Human FMs}

Human FMs were collected from patients with written consent following the decision from the Ethical Committee of the District of Zürich (study Stv07/2007). FMs were harvested after caesarian sections at term (between 37 and 39 weeks), stored in $\mathrm{NaCl}$, and used the same day as collected. All of them were negatively selected for HIV, hepatitis B, diabetes mellitus, and chlamydia.

\section{Adhesion Strength of the Umbrella-Shaped Glue Receptor to Intact FMs}

Fresh, intact FM, amnion side up was flattened out on a surface to remove wrinkles, put on a plate, and clamped with an 8 $\mathrm{cm}$-diameter aluminum cylinder (Fig. 2) minimizing stretching of the FM. The FM was kept damp with $0.9 \%$ saline solution. A small loop was added to the umbrellas to allow them to be pulled away from the membrane. $100 \mu \mathrm{L}$ of bioadhesive was added under the umbrella using a $200-\mu \mathrm{L}$ pipette and the umbrella was pressed down, to mimic the pulling of the device against the amnion. To ensure the bioadhesive was able to set in a wet environment, $0.9 \%$ saline solution was poured over the model. The umbrellas were pressed against the amnion for $1 \mathrm{~min}$ and left for a total of $15 \mathrm{~min}$ to ensure that the glue was fully polymerized. Then, the adhesion strength was quantified by using a dynamometer (Pesola AG, Schindellegi, Switzerland; ref. DO29/FH27) to pull the umbrella via the attached loop until it released from the amnion. This procedure was done with umbrellas made of silicon and PTFE in combinations with Histoacryl ${ }^{\circledR}$ and Glubran $2^{\circledR}$ ( $n=3$ for each group) since in our previous study they showed a significantly higher adhesion to FM than fibrin glue [17]. All values for adhesion strength tests were compared with a 1-way ANOVA using the Kruskal-Wallis test on IBM SPSS Statistics to judge statistical significance. Statistical significance was accepted for $p<0.05$.

\section{FM Defect Sealing Procedure on Pregnant Sheep Model} Animal Handling

Animal housing and all procedures and protocols were approved by the Cantonal Veterinary Office, Zurich, Switzerland, under license number ZH214/18. Housing and experimental procedures were in accordance with the Swiss Animal Protection law 
Fig. 3. Adhesion strength of the umbrella receptors glued with Glubran2 or Histoacryl on the ex vivo model $n=3$ for all combinations). PTFE, polytetrafluoroethylene.

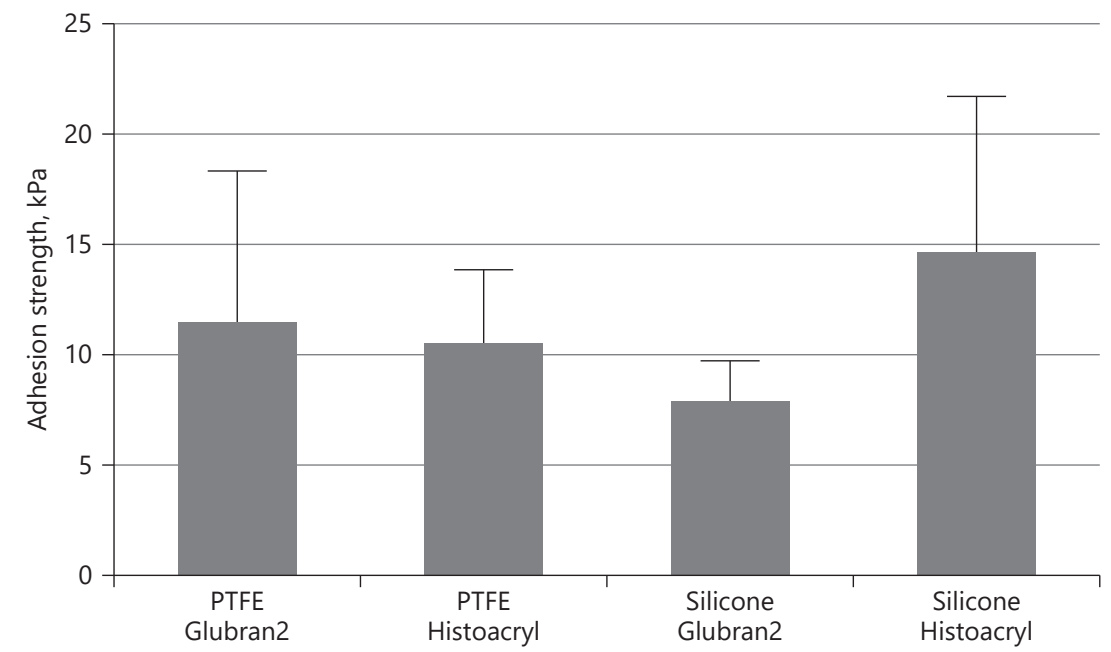

and conformed with European Directive 2010/63/EU of the European Parliament and of the Council of 22 September 2010 on the Protection of Animals Used for Scientific Purposes and to the Guide for the Care and Use of Laboratory Animals.

Two time-pregnant Swiss White Alpine ewes (gestational age 73 and 79 days) were used in this study. Both of the ewes were pregnant with twins.

Ewes were anesthetized by iv injection of ketamine hydrochloride (Ketasol ${ }^{\circledR}$-100; Graeub AG, Berne, Switzerland; 3 mg/kg BW) in combination with midazolam (Dormicum ${ }^{\circledR}$; F. Hoffmann-La Roche Ltd, Basel, Switzerland; $0.3 \mathrm{mg} / \mathrm{kg} \mathrm{BW)} \mathrm{and} \mathrm{pro-}$ pofol (Propofol-Lipuro ${ }^{\circledR}$; B. Braun Medical AG, Sempach, Switzerland; $2-5 \mathrm{mg} / \mathrm{kg} \mathrm{BW}$ ). After intubation, anesthesia was maintained by positive pressure ventilation (fresh gas flow 1-1.5 L/ $\mathrm{min}, 12-15$ breaths $/ \mathrm{min}$, tidal volume $5-10 \mathrm{~mL} / \mathrm{kg}, \mathrm{FiO} 20.5$ ) with isoflurane $(2-3 \%)$ in oxygen/air mixture. Preoperative antibiotic treatment was performed by intravenous administration of amoxicillin/clavulanic acid (Co-Amoxi-Mepha; Mepha Pharma AG, Basel, Switzerland; $1.2 \mathrm{~g}$ ). Analgesia was ensured through a constant rate infusion of sufentanyl (Sufenta Forte ${ }^{\circledR}$; Janssen-Cilag AG, Zug, Switzerland; $5 \mu \mathrm{g} / \mathrm{kg} \mathrm{BW/h}$ i.v.) and ketamine (Ketasol $^{\circledR}$ - 100 ; Graeub AG; $8 \mathrm{mg} / \mathrm{kg} / \mathrm{h}$, i.v.) throughout the intervention. A ropivacain infiltration block (Ropivacain Sintentica 1\%; Sintetica S.A., Mendrisio, Switzerland; $8-10 \mathrm{~mL}$ ) was set in the surgical area. Ringer solution was administered intravenously at an infusion rate of about $5 \mathrm{~mL} / \mathrm{kg} / \mathrm{h}$ for fluid substitution during surgery.

After surgery and after completion of data collection, the ewes were euthanized with Na-Pentobarbital (75 mg/kg BW). Fetuses were euthanized with Na-Pentobarbital (75 mg/kg BW), injected in the umbilical vein or intracardially.

Operation and Sealing Procedure

During the surgery, the ewe was in spine position. An infraumbilical midline laparotomy was performed to expose the uterus. A laparoscopic port was inserted at the distal end of the uter- us horns for camera insertion. Ringer solution was injected to fill the cavity to increase visibility and to allow optimal punching of the FM. To simulate a fetoscopic intervention, a 10-Fr trocar (Check-Flo Performer ${ }^{\circledR}$ Introducer; Cook Medical) was then mounted on an obturator (Anklin AG, Reinach, Switzerland) and inserted through the uterine wall into the amniotic sac at a $45^{\circ}$ angle. The umbrella-shaped glue receptors were crimped by hand and pushed into the applicator described above. Then the applicator was inserted in the 10-Fr trocar. The success rate of insertion was observed. Under endoscopic guidance, the umbrellashaped glue receptor was pushed out of the device into the amniotic cavity and pulled against the amniotic membrane. The success rate of deployment of the umbrella-shaped glue receptors was documented. To ensure that the glue receptor was completely filled, $400 \mu \mathrm{L}$ of adhesive was injected into the umbrella-shaped glue receptor through the injection inlets connected to a syringe. After $20 \mathrm{~s}$ of polymerization, the umbrella was released and the application device was removed, leaving the umbrella glued on the inside of the amniotic membrane. Since the volume of leakage is hard to measure on the surface of the wet uterus and the flow depends on the pressure and volume of the amniotic sac, leakage of amniotic fluid was assessed qualitatively by visual observation directly after implantation. A total of 4-5 implants were placed per uterine horn. In total, 9 implants were inserted and deployed. Of those 9, 1 application was used as the negative control, where the glue was injected in the amniotic cavity with the umbrella not in contact with the amnion. The other 8 devices were placed correctly onto the FM. From those, 2 were silicone with Glubran $2^{\circledR}$, 3 were PTFE with Glubran $2^{\circledR}$, and 3 PTFE with Histoacryl ${ }^{\circledR}$. Their combinations were done in a random order to minimize the effect of training on the output. After $4 \mathrm{~h}$ under anesthesia, common cow's milk was injected in the amniotic cavities to visualize potential leakage at the implant sites. Ewes and fetuses were then euthanized, and tissue samples were collected for histological analysis. 
Fig. 4. In vivo minimally invasive implantation of the umbrella receptor. a-f The steps for the implantation of the device. In a, the uterus is punched with a trocar, which is used to slide and place the 10-Fr catheter, as seen in $\mathbf{b}$. In $\mathbf{c}$, the trocar is removed to enable the insertion of the applicator and in $\mathbf{d}$ the introduction of the umbrella. In e, the umbrella is deployed and in f glued on the amniotic membrane. g Experimental setup. The uterus is exposed and the surgeon performs the application holding the 10-Fr catheter (blue tube) with one hand. $\mathbf{h}$ Leakage test. Milk is injected through the endoscope port (left on the image). i Leakage (yellow arrow) and tight sealing (yellow asterisk) of defects 4 h postop ( $n=8$ umbrellas implanted). $\mathbf{j}$ The count of tight and leaking implants right after implantation and after $4 \mathrm{~h}$ is summarized.
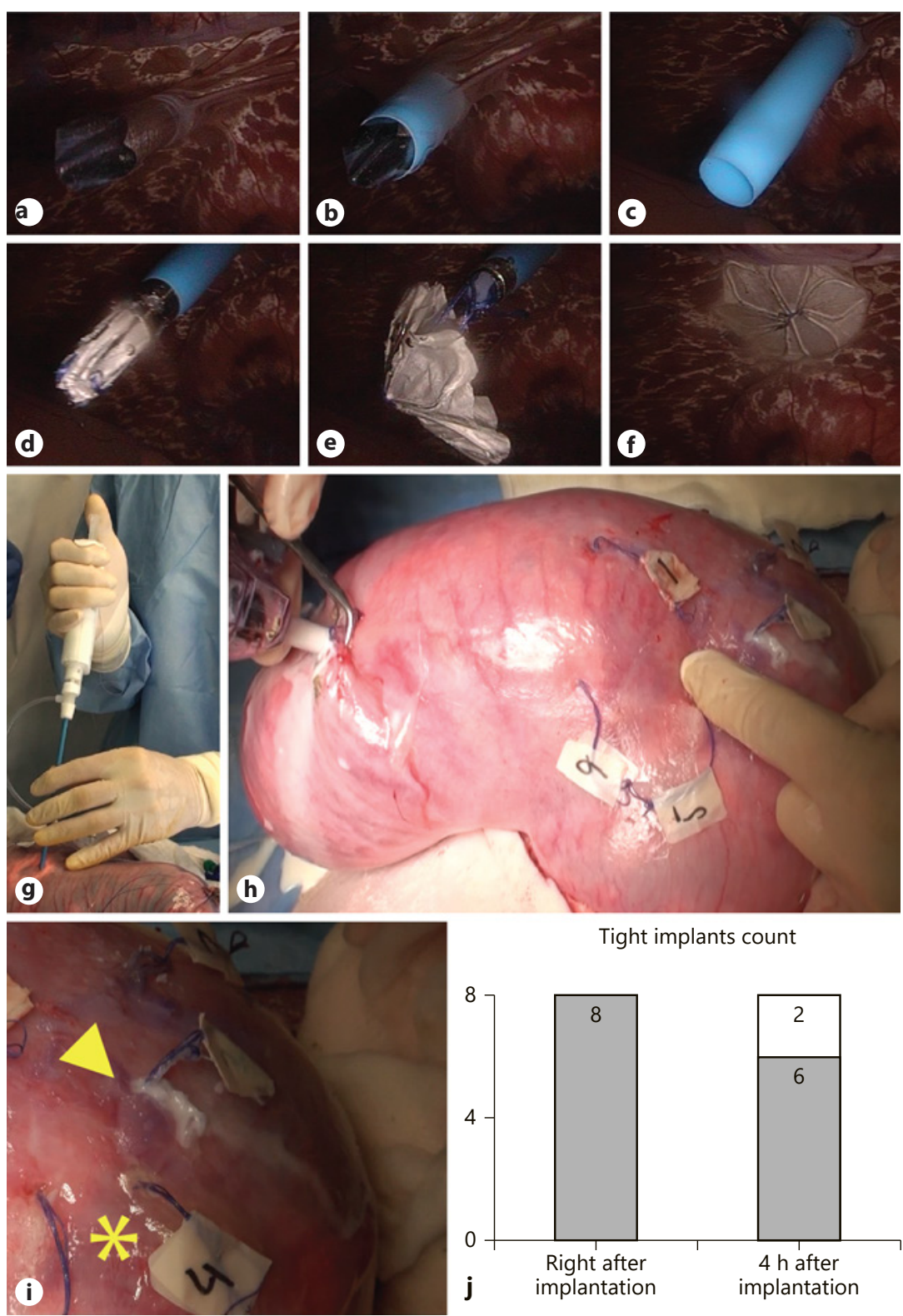

Tight implants count

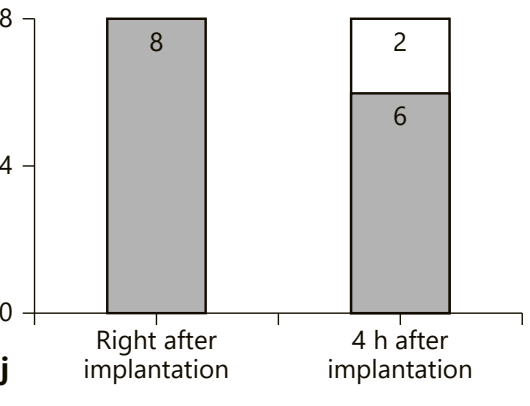

\section{Results}

\section{Adhesion Strength of the Umbrella-Shaped Glue \\ Receptor to Intact FMs}

To validate the use of adhesives and umbrella-shaped glue receptors, the adhesion strength was measured ex vivo. These adhesion measurements showed great variability within and between the different groups (Fig. 3).
The silicone umbrella together with Histoacryl ${ }^{\circledR}$ showed the greatest adhesive strength $(14.67 \pm 7.05 \mathrm{kPa})$. The PTFE umbrellas showed similar adhesion strength with both Glubran $2^{\circledR}$ and Histoacryl ${ }^{\circledR}(11.44 \pm 6.9 \mathrm{kPa}$ and $10.5 \pm 3.3 \mathrm{kPa}$, respectively). The silicone - Glubran $2^{\circledR}$ combination showed the smallest adhesion strength (7.9 $\pm 1.8 \mathrm{kPa})$. No significant difference was observed between the groups $(p=0.62)$. 
FM Defect Sealing Procedure on Pregnant Sheep Model Defect Sealing in vivo

After the adhesion strength was evaluated ex vivo, the next step consisted of evaluating if the umbrella could be applied precisely in vivo. Two minutes before implantation, the umbrella-shaped glue receptors were crimped and loaded into the insertion tube that was then pushed in the 10-Fr sheath introducer. While the PTFE-coated glue receptors could easily be deformed whilst remaining intact in all cases $(n=7 ; 100 \%)$, the silicone-coated umbrellas were brittle and their crimping caused cracking of the silicone with formation of holes, which impaired their capacity to gather glue. Two out of 6 silicone-coated glue receptors (33\%) were successfully loaded without damaging their coating. Figure $4 \mathrm{a}-\mathrm{f}$ shows the application steps of one of the umbrella-shaped glue receptors recorded by the endoscope. The insertion and deployment of the loaded umbrella-shaped glue receptors were successful in all the cases ( $n=9,100 \%$ of the deployed glue receptors). One PTFE-coated glue receptor was used as negative control. Here, the glue was applied deliberately before correctly positioning the umbrella. In this case, leakage of amniotic fluid was observed. All the other umbrellashaped glue receptors (6 PTFE, 2 silicone coated) could be positioned correctly on the defect, and injection of the tissue glue resulted in stable fixation of the glue receptor to the amnion ( $n=8,100 \%$ of the glue receptors). A slight milk flow was visualized on the surface of the uterus in 2 of the 8 implants (Fig. 4h, i yellow arrow), both being PTFE-covered umbrellas glued with Glubran $2^{\circledR}$. One of the devices that showed leakage was already detached, but not broken during the implantation of the next umbrella. The other 6 glue receptors (3 PTFE with Histoacryl, 1 PTFE with Glubran $2^{\circledR}$, and 2 Silicone with Glubran $2^{\circledR}$ ) continued to show a watertight seal ( $75 \%$ of the glued glue receptors, Fig. 4i yellow asterisk).

In some cases, presence of polymerized adhesive was observed on the surface of the uterus around the defects. The sutures used to pull and hold the umbrellas against the FM were also still present and visible on the outside. In addition, no complications or signs of maternal and fetal distress were monitored during surgeries and vital signs of both sheep remained constant until euthanasia.

\section{Discussion}

In the present study, we tested our previously developed minimally invasive device for the sealing of FM defects in pregnant sheep. For this, we coated the umbrella- shaped glue receptors with clinically approved materials and optimized their adhesion to FMs using different tissue glues ex vivo and in vivo. We managed to have a very reliable deployment of the umbrella-shaped glue receptors (100\%), and their adhesion to the FMs 4 h post-surgery was proven to be watertight in most of the cases (75\%). In addition, we did not notice a significant difference when using different types of cyanoacrylate adhesives. Finally, we recognized that silicone was not well suited for the use in our device because of multiple observations of silicone breakage upon crimping in the delivery device. Overall, our work represents an important step toward translating this technology for clinical application.

\section{Adhesion Strength of the Umbrella-Shaped Glue}

\section{Receptor to Intact FMs}

So far, the adhesion strength of different glues has only been examined on dry FMs and with Degrapol ${ }^{\circledR}$ (not a CE-marked material)-coated umbrellas [17]. Here, to advance our technology toward clinical application, we relied on different gluing and coating materials that are approved for clinical use. Additionally, to mimic in vivo conditions we conducted the ex vivo experiments in a wet environment, which by provision of hydroxyl ions supports the polymerization of cyanoacrylates. The strong adhesion of both Glubran $2^{\circledR}$ and Histoacryl ${ }^{\circledR}$ to PTFE and to amnion is very promising. While the adhesion strength of PTFE with Histoacryl ${ }^{\circledR}$ and Glubran $2{ }^{\circledR}$ was comparable, the variability of the measurements was lower with Histoacryl ${ }^{\circledR}$. These similar adhesion properties were previously reported in a publication comparing Glubran $2^{\circledR}$ to Histoacryl ${ }^{\circledR}$ in another animal study [22]. However, one has to keep in mind that an ex vivo study showed disruption of the epithelium of the amnion layer in histological analysis after contact with Histoacryl ${ }^{\circledR}$ [12]. Potential causes are the heat-inducing reaction of Histoacryl ${ }^{\circledR}$ and/or the embedment procedure for histologic analysis and need further investigation [12]. Despite very promising results in terms of adhesion strength, silicone-coated umbrellas should be disregarded from further experiments as they were found to be significantly more brittle, with $66 \%$ of them becoming defective during the process of loading them into the application device.

\section{FM Defect Sealing Procedure on Pregnant Sheep Model}

Other approaches to counter the risks of preterm birth have been developed previously but none have 
achieved clinical standards. Some reviews have summarized the development of other methods to prevent iPPROM along with their pros and cons $[4,18]$. For example, the application of platelet and cryoprecipitate (Amniopatch) has been tested, but the requirement of an additional puncture, the lack of precise deposition, and reported fetal death due to vasoactive effect of platelets might explain the questionable results so far $[23,24]$. Promising alternatives, like collagen plugs or decellularized amnion also made their way to in vivo studies in animals and in humans. Despite encouraging results in the rabbit model, regeneration of the FMs did not occur, and in humans, no decrease in iPPROM was observed $[5,25]$. The reason for this might be the lack of longterm mechanical support and tightness of the puncture due to the fast degradation of the collagen plugs. It might also result in side reactions to the degraded biomaterial. Similarly, application of fibrin sealants did not provide long-term support and lacked in providing stability to the defect $[26,27]$. Mussel-mimetic glue was shown to be a good future candidate as an alternative adhesive working in wet environments [15]. It was not used in this study because it is a 2-component glue making a controlled polymerization harder and it is not accepted for medical use. Healing-inducing materials, which count on stimulating queues to regenerate the FMs and fulfill the requirements for preventing iPPROM, are in a very promising state of development and deserve further investigation $[6,28,29]$. Similarly, other alternatives like the application of nanosilica-filled adhesive coacervate on lyophilized FMs that were previously inserted in the defect show good sealing properties ex vivo [30]. However, the development and regulatory path for the use of such materials in clinics will still be long and difficult. In addition, the approaches based on injection of material depend on minimally invasive deposition at the exact site of puncture, which is one important challenge with no solution so far.

Other surgical fields encounter similar problematics and served as inspiration for our development. For example, Angioseal ${ }^{\circledR}$ (Terumo Interventional Systems, Japan) uses minimally invasive interventional technology to close venous entry sites in cardiac surgery [31]. Their system enables the homeostasis and closure of the defect by applying a collagen patch on the vessel wall, which is made possible thanks to retention elements in the vessel lumen. Our approach uses a similar principle, where the umbrella-shaped glue receptor in the inside of the amniotic cavity serves as a container for an injectable strong adhesive. The purpose of it is to produce a watertight seal over the defect and mechanically secure the FM without relying on FM healing.

After our first ex vivo proof of concept, shown in our previous publication [17], the improved version of our device showed reliable and reproducible in vivo implantation of the umbrella receptors. Our results indicate that, if implanted correctly, this method can be used to seal the defect in a minimally invasive way. This was attested by the watertight seal observed in 6 of the 8 devices 4 h postsurgery. In addition, it showed that both glues performed equally well despite the detachment of 2 PTFE - Glubran $2{ }^{\circledR}$ combinations, which was not due to the adhesion strength of the glue but to application error. As for the 2 devices that showed leakage, 1 was detached during the implantation of the next umbrella, which was placed too close to it and suffered rough mechanical treatment. The other leakage was caused by the too early injection of glue before the umbrella was placed against the membrane, which resulted in a weak adhesion due to the insufficient quantity of glue in the umbrella.

Because of anatomic particularities of the sheep, other potential problems arising in the human like amnionchorion detachment was not possible to assess. Survival of both fetuses and mother, however, was confirmed in our study. The way to the clinics for such a technology will require extensive work to further improve the outcome. On one side, the glue application will need to be improved to prevent leakage in the amniotic cavity. Also, the volume of glue will have to be optimized in order to minimize the potential overflow of adhesive on the surface of the uterus. On the other side, safety testing needs to be done with the evaluation of the glue toxicity on the fetus, mother, and surrounding tissues. For this, we are planning long-term animal studies where the sheep will be operated, waken up, and sacrificed days later. This way, we will be able to analyze the long-term biological influence of the applied foreign materials on both the host and fetal tissues.

\section{Conclusion}

This study confirms that our previously established minimally invasive method for the preventive sealing of fetoscopy-induced FM defects is applicable in a clinically relevant sheep model. Next, the long-term in vivo performance of the sealing patch needs to be assessed to apprise its potential for clinical translation. 


\section{Statement of Ethics}

Human FMs were collected from patients with written consent following the decision from the Ethical Committee of the District of Zürich (study Stv07/2007). Animal in vivo procedures and protocols were approved by the Cantonal Veterinary Office, Zurich, Switzerland, under license number ZH214/18.

\section{Conflict of Interest Statement}

Prof. Dr. Roland Zimmermann, co-author of this study, declares to be Associate Editor of Fetal Diagnosis and Therapy. All other authors declare to have no conflict of interest.

\section{Author Contributions}

Y.R.D., N.O.-K., and M.E. conceived the project and designed the experiments. Y.R.D., U.M., L.V., S.S., M.W., M.E., and N.O.-K. performed the experiments and interpreted the data. Y.R.D., S.S, L.V., and N.O.-K. collected the samples. Y.R.D. and S.S. generated and analyzed the data. All contributed to the writing and revision of the manuscript. M.E., N.O.-K., and R.Z. supervised the project.

\section{Data Availability Statement}

All data generated or analyzed during this study are included in this article. Further inquiries can be directed to the corresponding author.

\section{Funding Sources}

This study was supported by the CTI/Innosuisse Grant 27063.1 PFLS-LS.

\section{References}

1 Senat MV, Deprest J, Boulvain M, Paupe A, Winer N, Ville Y. Endoscopic laser surgery versus serial amnioreduction for severe twinto-twin transfusion syndrome. N Engl J Med. 2004;351(2):136-44.

2 Danzer E, Sydorak RM, Harrison MR, Albanese CT. Minimal access fetal surgery. Eur J Obstet Gynecol Reprod Biol. 2003;108(1):313. RM

3 Gratacos E, Sanin-Blair J, Lewi L, Toran N, Verbist G, Cabero L, et al. A histological study of fetoscopic membrane defects to document membrane healing. Placenta. 2006;27(4-5): 452-6.

4 Beck V, Lewi P, Gucciardo L, Devlieger R. Preterm prelabor rupture of membranes and fetal survival after minimally invasive fetal surgery: a systematic review of the literature. Fetal Diagn Ther. 2012;31(1):1-9.

5 Engels AC, Van Calster B, Richter J, DeKoninck P, Lewi L, De Catte L, et al. Collagen plug sealing of iatrogenic fetal membrane defects after fetoscopic surgery for congenital diaphragmatic hernia. Ultrasound Obstet Gynecol. 2014;43(1):54-9.

6 Kivelio A, Ochsenbein-Koelble N, Zimmermann R, Ehrbar M. Engineered cell instructive matrices for fetal membrane healing. Acta Biomater. 2015;15:1-10.

7 Luks FI, Deprest JA, Peers KH, Steegers EA, van der Wildt B. Gelatin sponge plug to seal fetoscopy port sites: technique in ovine and primate models. Am J Obstet Gynecol. 1999; 181(4):995-6.

8 Pathak B, Khan A, Assaf SA, Miller DA, Chmait RH. Amniopatch as a treatment for rupture of membranes following laser surgery for twin-twin transfusion syndrome. Fetal Diagn Ther. 2010;27(3):134-7.
9 Quintero RA, Morales WJ, Allen M, Bornick PW, Arroyo J, LeParc G. Treatment of iatrogenic previable premature rupture of membranes with intra-amniotic injection of platelets and cryoprecipitate (amniopatch): preliminary experience. Am J Obstet Gynecol. 1999;181(3):744-9.

10 Roman S, Bullock AJ, Anumba DO, MacNeil S. Development of an implantable synthetic membrane for the treatment of preterm premature rupture of fetal membranes. J Biomater Appl. 2016;30(7):995-1003.

11 Cortes RA, Wagner AJ, Lee H, Clifton MS, Grethel E, Ha Yang S, et al. Pre-emptive placement of a presealant for amniotic access. Am J Obstet Gynecol. 2005;193(3):1197-203.

12 Bilic G, Brubaker C, Messersmith PB, Mallik AS, Quinn TM, Haller C, et al. Injectable candidate sealants for fetal membrane repair: bonding and toxicity in vitro. Am J Obstet Gynecol. 2010;202(1):85-9. el

13 Ochsenbein-Kolble N, Jani J, Lewi L, Verbist G, Vercruysse L, Portmann-Lanz B, et al. Enhancing sealing of fetal membrane defects using tissue engineered native amniotic-scaffolds in the rabbit model. Am J Obstet Gynecol. 2007;196(3):263-5.

14 Haller CM, Buerzle W, Brubaker CE, Messersmith PB, Mazza E, Ochsenbein-Koelble N, et al. Mussel-mimetic tissue adhesive for fetal membrane repair: a standardized ex vivo evaluation using elastomeric membranes. Prenat Diagn. 2011;31(7):654-60.

15 Haller CM, Buerzle W, Kivelio A, Perrini M, Brubaker CE, Gubeli RJ, et al. Mussel-mimetic tissue adhesive for fetal membrane repair: an ex vivo evaluation. Acta Biomater. 2012; 8(12):4365-70.
16 Deprest J, Jani J, Lewi L, Ochsenbein-Kölble N, Cannie M, Doné E, et al. Fetoscopic surgery: encouraged by clinical experience and boosted by instrument innovation. Semin Fetal Neonatal Med. 2006;11(6):398-412.

17 Devaud YR, Züger S, Zimmermann R, Ehrbar M, Ochsenbein-Kölble N. Minimally invasive surgical device for precise application of bioadhesives to prevent iPPROM. Fetal Diagn Ther. 2019;45(2):102-10.

18 Winkler SM, Harrison MR, Messersmith PB Biomaterials in fetal surgery. Biomater Sci. 2019;7(8):3092-109.

19 Dilege E, Deveci U, Erbil Y, Dinççağ A, Seven R, Ozarmagan S, et al. N-butyl cyanoacrylate versus conventional suturing for fixation of meshes in an incisional hernia model. J Invest Surg. 2010;23(5):262-6.

20 Kull S, Martinelli I, Briganti E, Losi P, Spiller D, Tonlorenzi S, et al. Glubran2 surgical glue: in vitro evaluation of adhesive and mechanical properties. J Surg Res. 2009;157(1):e1521.

21 Li Y. In vitro characterization of cyanoacrylate embolic glues used for vascular embolization. Université de Technologie de Compiègne: HAL; 2017.

22 Vakalopoulos KA, Wu Z, Kroese LF, Jeekel J, Kleinrensink GJ, Dodou D, et al. Sutureless closure of colonic defects with tissue adhesives: an in vivo study in the rat. Am J Surg. 2017;213(1):151-8.

23 Quintero RA, Morales WJ, Allen M, Bornick PW, Arroyo J, LeParc G. Treatment of iatrogenic previable premature rupture of membranes with intra-amniotic injection of platelets and cryoprecipitate (amniopatch): preliminary experience. Am J Obstet Gynecol. 1999;181(3):744-9. 
24 Louis-Sylvestre C, Rand JH, Gordon RE, Salafia CM, Berkowitz RL. In vitro studies of the interactions between platelets and amniotic membranes: a potential treatment for preterm premature rupture of the membranes. Am J Obstet Gynecol. 1998;178(2):287-93.

25 Gratacos E, Wu J, Yesildaglar N, Devlieger R, Pijnenborg R, Deprest JA. Successful sealing of fetoscopic access sites with collagen plugs in the rabbit model. Am J Obstet Gynecol. 2000;182(1 Pt 1):142-6.

26 Harmanli OH, Wapner RJ, Lontz JF. Efficacy of fibrin glue for in vitro sealing of human chorioamniotic membranes. J Reprod Med. 1998;43(11):986-90.
27 Young BK, Roqué H, Abdelhak YE, Poiolek D, Demopulos R, Lockwood CJ. Minimally invasive endoscopy in the treatment of preterm premature rupture of membranes by application of fibrin sealant. J Perinat Med. 2000;28(4):326-30.

28 Ochsenbein-Kolble N, Jani J, Lewi L, Verbist G, Vercruysse L, Portmann-Lanz B, et al. Enhancing sealing of fetal membrane defects using tissue engineered native amniotic scaffolds in the rabbit model. Am J Obstet Gynecol. 2007;196(3):263.e1-7.
29 Papadopulos NA, Van Ballaer PP, Ordoñez JL, Laermans IJ, Vandenberghe K, Lerut TE, et al. Fetal membrane closure techniques after hysteroamniotomy in the midgestational rabbit model. Am J Obstet Gynecol. 1998;178(5): 938-42.

30 Mann LK, Papanna R, Moise KJ, Byrd RH Popek EJ, Kaur S, et al. Fetal membrane patch and biomimetic adhesive coacervates as a sealant for fetoscopic defects. Acta Biomater. 2012;8(6):2160-5.

31 Nash JE, Evans DG. The Angio-Seal hemostatic puncture closure device. Concept and experimental results. Herz. 1999;24(8):597606 